\title{
Occupancy Factor Model for Exposure to Natural Radionuclides along the Coastline of Erongo Region, Namibia
}

\author{
Sylvanus A. Onjefu' ${ }^{1,2}$, Nnenesi A. Kgabi ${ }^{3}$, Simeon H. Taole ${ }^{1}$, Owen P. L. Mtambo ${ }^{4}$, \\ Charles Grant ${ }^{5}$, Johann Antoine ${ }^{5}$ \\ ${ }^{1}$ Department of Physics and Electronics, North-West University, Mafikeng Campus, \\ Mmabatho, South Africa \\ ${ }^{2}$ Department of Natural and Applied Sciences, Namibia University of Science and Technology, \\ Windhoek, Namibia \\ ${ }^{3}$ Department of Civil and Environmental Engineering, Namibia University of Science and \\ Technology, Windhoek, Namibia \\ ${ }^{4}$ Department of Mathematics and Statistic, Namibia University of Science and Technology, \\ Windhoek, Namibia \\ ${ }^{5}$ International Centre for Environmental and Nuclear Sciences, University of the West Indies, \\ Mona Campus, Kingston, Jamaica \\ Email: *sonjefu@nust.na,nkgabi@nust.na, Simeon.Taole@nwu.ac.za,omtambo@nust.na, \\ Charle.grant@uwimona.edu.jm,johann.antoine@uwimona.edu.jm
}

Received 12 March 2016; accepted 17 May 2016; published 20 May 2016

Copyright @ 2016 by authors and Scientific Research Publishing Inc.

This work is licensed under the Creative Commons Attribution International License (CC BY). http://creativecommons.org/licenses/by/4.0/

(c) (i) 0pen Access

\begin{abstract}
In this study, an occupancy factor model was developed and used to calculate the average time spent for outdoor and indoor activities along the coastline of the Erongo region of Namibia. A closed ended questionnaire was developed and administered to 800 respondents who visited the coastline for leisure, occupational and other activities. The mean time allocated for leisure activities ranges from 13.00 to $1.00 \mathrm{~h}$, occupational mean time between 10.18 to $9.06 \mathrm{~h}$ and the values of other activities range from 16.66 to $11.00 \mathrm{~h}$. The average computed time spent outdoor was found to be $11.46 \mathrm{~h}$ and indoor calculated to be $12.54 \mathrm{~h}$. This shows an outdoor factor of 0.48 and indoor factor of 0.52 respectively. From the results obtained, the value of the absorbed dose rate ranged from 93.27 to $105.95 \mathrm{nGy} \cdot \mathrm{h}^{-1}$ and the annual effective dose rate ranged from 121.01 to 176.61 $\mu S v \cdot y^{-1}$ (UNSCEAR factor) and 292.60 to $413.63 \mu S v \cdot y^{-1}$ (present factor). The values obtained for annual effective dose are higher than the acceptable limit. However, from this study, we can conclude that the use of the UNSCEAR outdoor factor in the coastline will lead to underestimation of effective dose by $24 \%$ based on the present factor.
\end{abstract}

"Corresponding author.

How to cite this paper: Onjefu, S.A., Kgabi, N.A., Taole, S.H., Mtambo, O.P.L., Grant, C. and Antoine, J. (2016) Occupancy Factor Model for Exposure to Natural Radionuclides along the Coastline of Erongo Region, Namibia. Journal of Geoscience and Environment Protection, 4, 117-126. http://dx.doi.org/10.4236/gep.2016.45012 
Keywords

Model, Indoor, Outdoor, Leisure, Occupation, Effective Dose

\section{Introduction}

The exposure of human population to ionizing radiation from natural sources is a continuing and inescapable feature of human life on earth. There exist two main contributors to human exposure to natural occurring radioactive materials (NORMs). This includes high-energy cosmic ray particles incident on the earth's atmosphere and radioactive nuclides originating from the earth crust and present everywhere in the environment [1]. External exposures to NORMs arise from terrestrial radioisotopes present at trace levels in soil, sediments and building materials [2] [3]. Only those radioactive materials with half-lives comparable to the age of the earth, and their decay daughters, exist in significant quantities in these materials [4]. Irradiation is mainly by gamma radiation from radioactive nuclides in ${ }^{238} \mathrm{U}$ and ${ }^{232} \mathrm{Th}$ series and from ${ }^{40} \mathrm{~K}$ [5] [6]. There exist also exposures to anthropogenic sources that are largely due to medical and industrial activities [7] [8].

The level of exposure to NORMs at any giving location in an uncontaminated environment depends on features that characterize the environment. Some of these features include environmental variables such as local geology, erosion, run-off pattern, and land utilization. All which have direct effect by modifying the soil composition and hence the natural radioactivity concentration levels [9].

There have been concerns about the exposure of humans to radioactive materials from natural and anthropogenic sources. The potential adverse health implications following environmental contaminations by NORMs have prompted some studies of many facets of environmental phenomena (water, soil, sediment, air, and plant) to ascertain the levels of radioactivity. For example, studies have shown that long term exposure to radionuclides through inhalation has severe health consequences such as chronic lung diseases, acute leucopoenia, anaemia and necrosis of the mouth [10]. Exposure to radium causes bone weakening, cranial and nasal tumours [11]. Other health hazards caused by exposure to radiation from certain isotopes include lung cancer, pancreas, hepatic, cataracts, sterility, leukaemia, bone, and skin and kidney cancer [12]-[14].

Some studies have shown that parts of the Erongo region of Namibia have high background radiation levels due to vast deposit of uranium bearing ores [15]-[17]. The amount of radiation absorbed by population in the coastline of the Erongo region over the years has not been fully evaluated. This may have been informed by the inability to properly evaluate the average time spent indoor or outdoor by the population along the coastline. In the study of natural occurring radioisotopes of terrestrial origin, the knowledge of the outdoor and indoor occupancy factors forms the basis for the evaluation of the doses accruing to the population [18] [19]. For instance, in West Africa, a study by Arogunjo et al. [20] re-evaluated the occupancy factors for effective dose estimated in tropical environment. Their finding shows an outdoor factor of 0.3 and 0.22 for rural and urban dwellers, respectively. The rural and urban outdoor factor was found to be $50 \%$ and $10 \%$ above the world average by the UNSCEAR. Similarly, in the same country [21], another study was undertaking where a model was developed to evaluate occupancy factor for exposure to atmospheric radiation by urban and rural dwellers. The result showed that an average city dweller spent $20.33 \%$ of the total time per day exposed to radiation from the atmosphere while an average rural dweller spent $26.88 \%$ of the time. Interestingly, these models have pointed to the need to calculate the outdoor and indoor occupancy factor of a given environment with a view to assessing the actual exposure doses to the population.

In this study, a mathematical representation of time spent for outdoor and indoor activities for the coastline of the Erongo region of Namibia is modelled. The coastline is a well renowned Namibian holiday destination for both local and international tourists. The Region is however rich in Uranium deposits, which necessitates the comprehensive measurement and monitoring methods for exposure to natural radionuclides.

\section{Materials and Methods}

\subsection{Study Area}

The study focused on three beaches in the towns of Walvis Bay, Swakopmund and Henties Bay along the coas- 
tline of Erongo region of Namibia (see Figure 1). According to Namibia 2011 population and housing census preliminary result, Erongo region has a population of 150,400 and a total land area of 63,549 Sq.Km [22]. The towns of Walvis Bay, Swakopmund and Henties Bay are located on longitude $22^{\circ} 57^{\prime} 22^{\prime \prime}$ South and latitude $14^{\circ} 30^{\prime} 19^{\prime \prime}$ East; longitude $22^{\circ} 4^{\prime} 59^{\prime \prime}$ South and latitude 14 $31^{\circ} 59^{\prime \prime}$ East; longitude $22^{\circ} 55^{\prime} 22^{\prime \prime}$ South and latitude $14^{\circ} 30^{\prime} 19^{\prime \prime}$ East respectively. Much of the region is occupied by the Namib Desert which stretches parallel to the coast for about 120 to $150 \mathrm{~km}$ land. The towns of Walvis Bay, Swakopmund and Henties Bay are $60 \mathrm{~km}, 40 \mathrm{~km}$ and $80 \mathrm{~km}$ from most of the active uranium mine sites. The region is arid and thus, the area has very little agricultural potential. However, only $10 \mathrm{Sq} \cdot \mathrm{Km}$ of the region is suitable for cultivation. These are the area of small scale farming in the Swakop River bed, as well as small areas at Omaruru and Okombahe. Some industrial activities however strive in the region. Some of which are fishing, tourism and uranium mining.

\subsection{Activity Concentration Measurement}

In order to evaluate the concentration of natural radioactivity in shore sediments along the coastline of the Erongo region, shore sediment samples were collected at random from 78 points from the beaches of Walvis Bay, Swakopmund and Henties Bay between October and December 2013. These points were marked based on the Global Positioning System (GPS) and designated to be representative of the concentrations of natural radioactive materials from the three beaches. The sampling points were carefully chosen to represent areas where

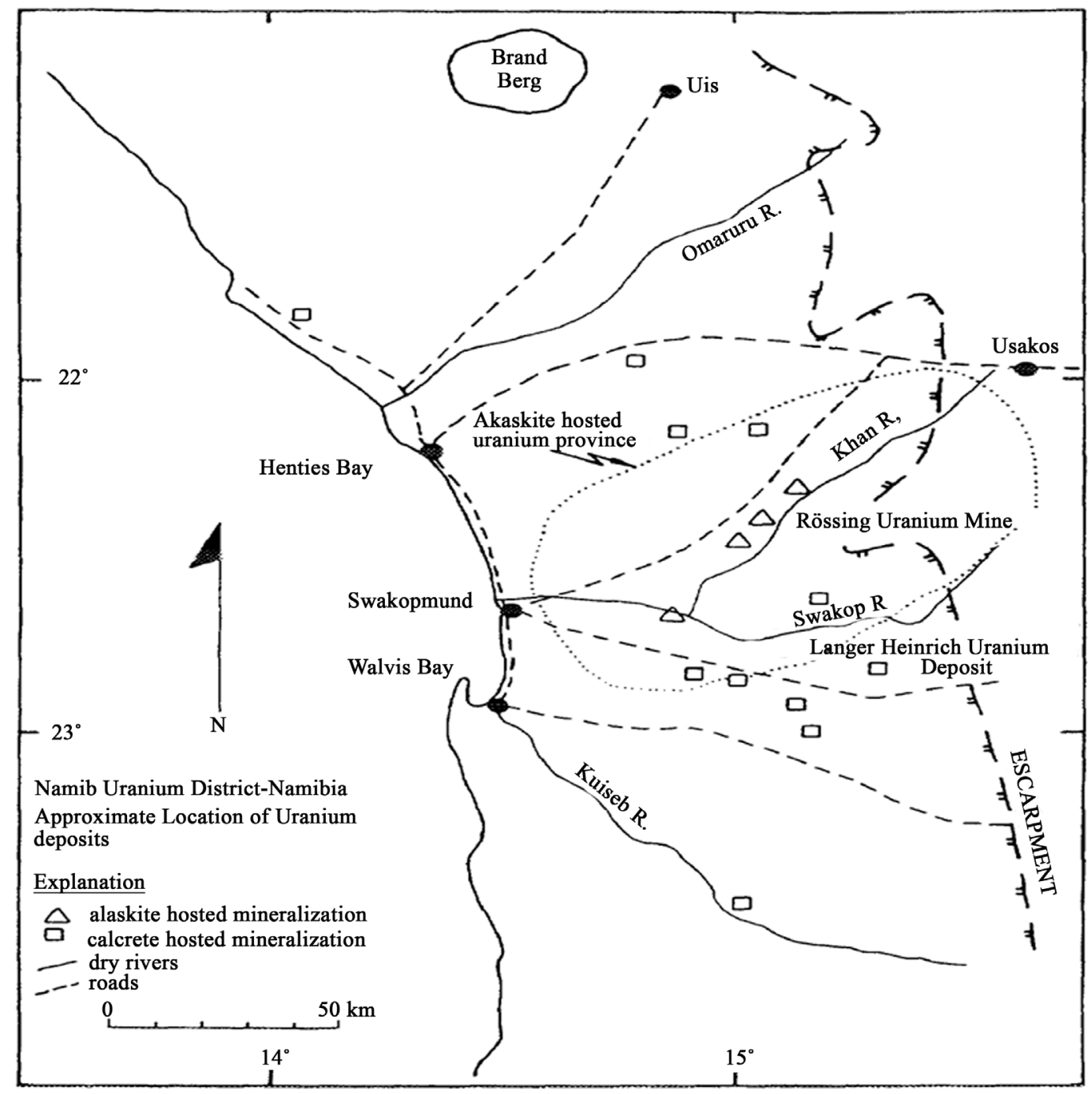

Figure 1. Map showing sampling locations and some uranium mines. 
human population are involved in various activities such as; leisure, occupation and others. At each location, shore sediment samples were taken from an approximate 7 to 10 meters away from high tide at a depth of 20 centimetres by using hand scooper. After each sample was cleared of debris it was allowed to dry at a temperature of $110^{\circ}$ for 24 hours. Prior to gamma analysis, the samples were then left to stand for thirty (30) days for secular equilibrium to be reached between long-lived parent radionuclide and their short-lived daughter radionuclides in the ${ }^{238} \mathrm{U}$ and ${ }^{232} \mathrm{Th}$ decay series. On the attainment of secular equilibrium, the samples were then counted for 8 hours on a gamma spectroscopy system with HPGe Detector housed in the International Centre for Environmental and Nuclear Sciences, University of the West Indices Mona Campus, Kingston, Jamaica with 70\% efficiency and a resolution of $1.8 \mathrm{keV}$ at the $1.3 \mathrm{MeV}$ Cobalt line. The detector was calibrated with respect to energy and efficiency before measurements. Standards of known concentrations of radionuclides were used. Background measurement which is the natural occurring radioactivity were taken and appropriately subtracted from the measured gamma ray spectrum of each samples in order to obtain net counts for the samples. The spectrum obtained from the standards was then employed to carryout energy and efficiency calibrations which were used in the determination of the activity concentration of the radioactive nuclides in $\mathrm{Bq} \cdot \mathrm{kg}^{-1}$.

\subsection{Experimental Data Collection}

A total of 800 closed ended questionnaires were administered to participants along the coastline in the beaches of Swakopmund, Walvis Bay and Henties Bay. The exposure-related activities of the studied population included leisure and work/occupation i.e. fishing, diving, walking, picnic at the shore, horse riding, sun bathing, relaxation at beach house, vendor, shop retailer, sanitation work and others.

Data from the questionnaires were used to calculate the outdoor and indoor occupancy factor. A model relating time budget for the various activities such as leisure, occupational and others that involves indoor and outdoor parameters has been developed.

\subsection{Modelling the Data}

The following assumptions were considered in the development of this model:

1) Absorption rate of NORMs is directly proportional to the amount of time spent in exposure.

2) Each population group was assumed to have a time fraction of leisure, occupation and other activities.

3) Each activity was assumed to have a time fraction of indoor and outdoor function.

4) The total time spent indoor and outdoor in a day is 24 hours for each population group.

5) Each activity was regarded as an independent time variable.

6) Indoor and outdoor time spent is linearly dependent on the activities.

If we consider " $P$ " to represent the time spent indoor and " $O$ " for the time spent outdoor for any given activity, and considering assumptions four (4) above. We have that;

$$
I+O=24
$$

The indoor time component was modelled as;

$$
I=\sum_{k=1}^{3} \lambda_{k} A_{k}=\lambda_{1} A_{1}+\lambda_{2} A_{2}+\lambda_{3} A_{3}
$$

where $\lambda_{k}=$ indoor fractional time parameter for $k^{\text {th }}$ activity.

$A_{k}=$ observed total time spent for $k^{\text {th }}$ activity.

The outdoor time component was modelled as;

$$
O=\sum_{k=1}^{3} \sigma_{k} A_{k}=\sigma_{1} A_{1}+\sigma_{2} A_{2}+\sigma_{3} A_{3}
$$

where $\sigma_{k}=$ outdoor fractional time parameter for $k^{\text {th }}$ activity.

Adding Equations (2) and (3), leads to

$$
I+O=\sum_{k=1}^{3} \lambda_{k} A_{k}+\sum_{k=1}^{3} \sigma_{k} A_{k}
$$

From Equations (1) and (4), we obtain 


$$
24=\sum_{k=1}^{3} \lambda_{k} A_{k}+\sum_{k=1}^{3} \sigma_{k} A_{k}
$$

Substituting Equation (2) into Equation (5), yields

$$
24=I+\sum_{k=1}^{3} \sigma_{k} A_{k}
$$

It follows that

$$
I=24-\sum_{k=1}^{3} \sigma_{k} A_{k}
$$

Similarly, substituting Equation (3) into Equation (5)

$$
O=24-\sum_{k=1}^{3} \lambda_{k} A_{k}
$$

Adding Equation (2) and Equation (6)

$$
\begin{gathered}
2 I=24+\sum_{k=1}^{3} \lambda_{k} A_{k}-\sum_{k=1}^{3} \sigma_{k} A_{k} \\
I=12+\sum_{k=1}^{3}\left(\frac{\lambda_{k}-\sigma_{k}}{2}\right) A_{k}
\end{gathered}
$$

Similarly, adding Equation (3) and Equation (7), we obtain

$$
O=12-\sum_{k=1}^{3}\left(\frac{\lambda_{k}-\sigma_{k}}{2}\right) A_{k}
$$

Let $T_{k}=\left(\frac{\lambda_{k}-\sigma_{k}}{2}\right)$, where $T_{k}$ represents the total fractional time parameter for $k^{\text {th }}$ activity. Therefore;

$$
\begin{aligned}
& I=12+\sum_{k=1}^{3} T_{k} A_{k} \\
& O=12-\sum_{k=1}^{3} T_{k} A_{k}
\end{aligned}
$$

Therefore the sum of (10) and (11) equals (1).

The model (Equations (10) and (11)) were used in MATLAB to determine the fractional time parameter estimates for indoor and outdoor occupancy.

\section{Results and Discussion}

\subsection{Occupancy Factor}

Table 1 presents the mean time allocated for each activity. Table 2 is the value of the estimated indoor and outdoor fractional time parameter for each activity while Table 3 and Table 4 represent the values of the total fraction of time parameters for each group and the computed time spent indoor and outdoor. Using the factor model above, the computed time spent outdoor in the coastline of the Erongo region (Table 4) was obtained in the range from 18.59 to $8.40 \mathrm{~h}$ for leisure activities and 13.14 to $8.26 \mathrm{~h}$ for occupational related activities. The value for indoor activity was calculated to range from 15.60 to $5.41 \mathrm{~h}$ for leisure and 15.74 to $10.86 \mathrm{~h}$ for occupational related activities. The average time spent for outdoor activity by an average visitor to the coastline has been evaluated to be $11.46 \mathrm{~h}$. This accounted for $48 \%$ of the total time per day for which an individual maybe exposed to radioactive elements along the coastline. Similarly, the average time spent for indoor activities has been calculated to be $12.54 \mathrm{~h}$. This implies that on an average, visitors to the coastline spent $52 \%$ of their total time per day in indoor related activities. The outdoor occupancy factor of 0.48 for this present study is 2.4 times the UNSCEAR value of $0.2 \%$ or $20 \%$ which is significant. The data shows that the indoor factor of 0.52 for an average person who visit the coastline is $35 \%$ below the world average factor of 0.8 [19]. 
Table 1. The mean time allocated for each activity.

\begin{tabular}{cccc}
\hline Group & \multicolumn{3}{c}{ Activity } \\
\cline { 2 - 3 } Leisure-fishing & Leisure & Occupational & Others \\
Leisure-diving & 12.31 & 0.00 & 11.69 \\
Leisure-walking & 10.39 & 0.00 & 13.61 \\
Leisure-picnic at shore & 7.34 & 0.00 & 16.66 \\
Leisure-horse riding & 12.33 & 0.00 & 11.67 \\
Leisure-sun bathing & 10.00 & 0.00 & 14.00 \\
Leisure-relaxation at beach house & 10.79 & 0.00 & 13.21 \\
Occupation-vendor & 13.00 & 0.00 & 11.00 \\
Occupation-shop retailer & 1.32 & 10.18 & 12.51 \\
Occupation-sanitation worker & 1.00 & 9.58 & 13.42 \\
\hline
\end{tabular}

Table 2. Values of estimated indoor $(\lambda)$ and outdoor $(\sigma)$ fractional time parameter.

\begin{tabular}{|c|c|c|c|c|c|c|}
\hline \multirow[b]{3}{*}{ Group } & \multicolumn{6}{|c|}{ Activity } \\
\hline & \multicolumn{2}{|c|}{ Leisure } & \multicolumn{2}{|c|}{ Occupation } & \multicolumn{2}{|c|}{ Others } \\
\hline & $\sigma$ & $\lambda$ & $\sigma$ & $\lambda$ & $\sigma$ & $\lambda$ \\
\hline Leisure-fishing & 0.76 & 0.24 & $*$ & * & 0.79 & 0.21 \\
\hline Leisure-diving & 0.62 & 0.38 & * & * & 0.29 & 0.71 \\
\hline Leisure-walking & 0.72 & 0.28 & * & * & 0.32 & 0.68 \\
\hline Leisure-picnic at shore & 0.73 & 0.27 & * & * & 0.25 & 0.75 \\
\hline Leisure-horse riding & 0.49 & 0.51 & * & * & 0.25 & 0.75 \\
\hline Leisure-sun bathing & 0.53 & 0.47 & * & * & 0.32 & 0.68 \\
\hline Leisure-relaxation at beach house & 0.49 & 0.51 & * & $*$ & 0.46 & 0.54 \\
\hline Occupation-vendor & 0.85 & 0.15 & 0.91 & 0.09 & 0.22 & 0.78 \\
\hline Occupation-shop retailer & 1.00 & 0.00 & 0.45 & 0.55 & 0.22 & 0.78 \\
\hline Occupation-sanitation worker & 0.98 & 0.02 & 0.80 & 0.20 & 0.24 & 0.76 \\
\hline
\end{tabular}

*Not applicable.

Table 3. Values of the total fractional time parameters.

\begin{tabular}{cccc}
\hline & Activity & & \\
\hline & Group leisure $\left(T_{1}\right)$ & Occupation $\left(T_{2}\right)$ & Other $\left(T_{3}\right)$ \\
\hline Leisure-fishing & -0.26 & $*$ & -0.29 \\
Leisure-diving & -0.12 & $*$ & 0.21 \\
Leisure-walking & -0.22 & $*$ & 0.18 \\
Leisure-picnic at shore & -0.23 & $*$ & 0.25 \\
Leisure-horse riding & 0.01 & $*$ & 0.25 \\
Leisure-sun bathing & -0.03 & $*$ & 0.18 \\
Leisure relaxation at beach house & 0.01 & -0.41 & 0.04 \\
Occupation-vendor & -0.35 & 0.05 & 0.28 \\
Occupation-shop retailer & -0.50 & -0.30 & 0.28 \\
Occupation-sanitation worker & -0.48 & & 0.26 \\
\hline
\end{tabular}

\footnotetext{
*Not applicable.
} 
Table 4. Computed time spent outdoor and indoor.

\begin{tabular}{cccc}
\hline $\mathrm{s} / \mathrm{n}$ & Group & Outdoor & Indoor \\
\hline 1. & Leisure-fishing & 18.59 & 5.41 \\
2. & Leisure-diving & 10.39 & 13.61 \\
3. & Leisure-walking & 10.62 & 13.38 \\
4. & Leisure-picnic at shore & 11.92 & 12.08 \\
5. & Leisure-horse riding & 15.60 \\
6. & Leisure-sun bathing & 14.05 \\
7. & Leisure relaxation at beach house & 9.95 & 12.57 \\
8. & Occupation-vendor & 11.43 & 10.86 \\
9. & Occupation-shop retailer & 13.14 & 15.74 \\
10. & Occupation-sanitation worker & 8.26 & 12.54 \\
11. & Average & 11.96 & 12.54 \\
12. & Occupancy factor & 11.46 & 0.52 \\
13. & Percentage & 0.48 & $52 \%$
\end{tabular}

\subsection{Activity Concentration}

The mean specific activity concentrations obtained for shore sediment samples collected along the coastline of Erongo region are presented in Table 5 and a comparison of the absorbed dose and annual effective dose rate from the study areas with world average value (UNSCEAR) are shown in Table 6 and Figure 2 respectively. The activity concentrations of ${ }^{238} \mathrm{U},{ }^{232} \mathrm{Th}$ and ${ }^{40} \mathrm{~K}$ in the sediment samples ranged from 142.79 to $199.76 \mathrm{~Bq} \cdot \mathrm{kg}^{-1}$ with a mean of $173.00 \pm 8.8 \mathrm{~Bq} \cdot \mathrm{g}^{-1}$, 29.69 to $42.47 \mathrm{~Bq} \cdot \mathrm{kg}^{-1}$ with a mean of $37.77 \pm 2.7 \mathrm{~Bq} \cdot \mathrm{kg}^{-1}$ and 354.38 to $611.19 \mathrm{~Bq} \cdot \mathrm{kg}^{-1}$ with a mean of $441.78 \pm 2.5 \mathrm{~Bq} \cdot \mathrm{kg}^{-1}$, respectively.

\subsubsection{Absorbed Dose Rate (ADR)}

The absorbed dose rate calculation was based on the mean activity concentrations of ${ }^{238} \mathrm{U}$, ${ }^{232} \mathrm{Th}$ and ${ }^{40} \mathrm{~K}$ converted into dose rate on the bases of the UNSCEAR conversion factor [1].

$$
D=\left(0.462 C_{U}+0.604 C_{T h}+0.0417 C_{K}\right) \mathrm{n} \cdot \mathrm{Gyh}^{-1}
$$

where $D$ is the absorbed dose rate $\left(\mathrm{nGy} \cdot \mathrm{h}^{-1}\right), C_{U}, C_{T h}, C_{K}$

The average absorbed dose rate for all the sampled locations are above the world average value (51 nGy.h ${ }^{-1}$ ) [1].

\subsubsection{Annual Effective Dose Rate (AEDR)}

The annual effective dose received by visitors to the coastline was calculated from the absorbed dose rate by applying dose conversion factor of $0.7 \mathrm{~Sv} / \mathrm{Gy}$ and the occupancy factor for outdoor and indoor. According to UNSCEAR [1], the outdoor and indoor factors are $0.2(5 / 24)$ and 0.8 (19/24) respectively. The annual effective dose (outdoor) was determined using the following equations

$$
\begin{aligned}
& \text { AEDR(Outdoor })\left(\mu \mathrm{Sv} \cdot \mathrm{y}^{-1}\right) \\
& =(A D R) \mathrm{nGy} \cdot \mathrm{h}^{-1} \times 8760 \mathrm{~h} \times 0.7 \mathrm{~Sv} \cdot \mathrm{Gy}^{-1} \times 0.2 \times 10^{-3}(\text { UNSCEAR factor }) \\
& \text { AEDR }(\text { Outdoor })\left(\mu \mathrm{Sv} \cdot \mathrm{y}^{-1}\right) \\
& \left.=(A D R) \mathrm{nGy} \cdot \mathrm{h}^{-1} \times 8760 \mathrm{~h} \times 0.7 \mathrm{~Sv} \cdot \mathrm{Gy}^{-1} \times 0.48 \times 10^{-3} \text { (Present factor }\right)
\end{aligned}
$$




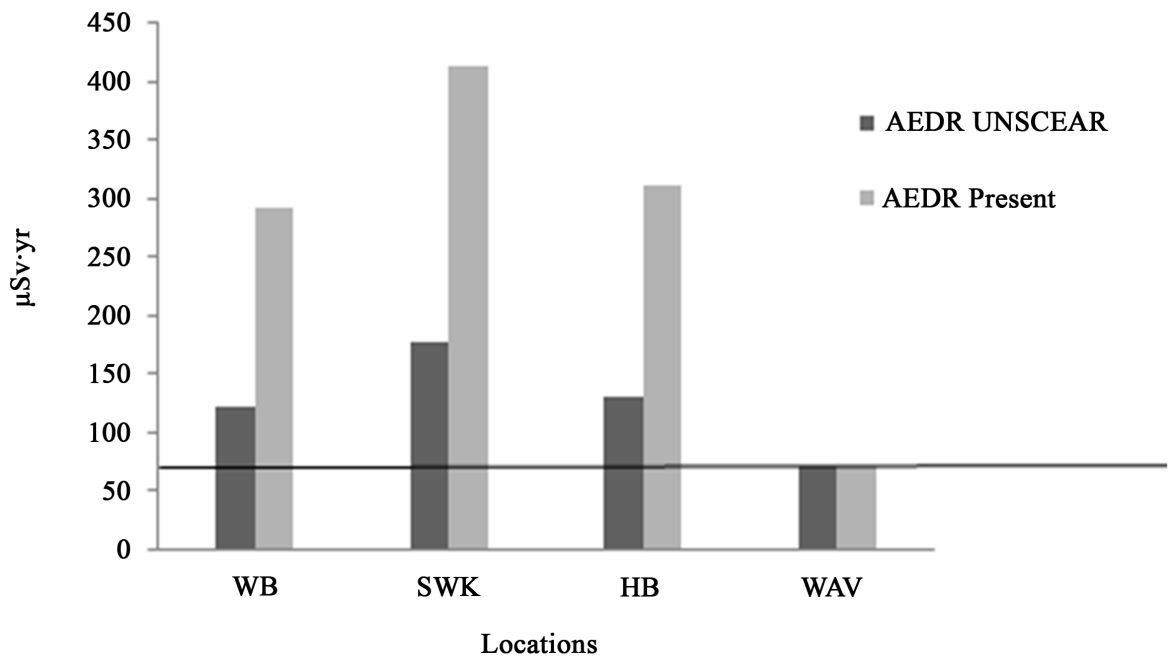

Figure 2. Comparison of effective dose rate of UNSCEAR and present factors with world average values.

Table 5. Mean activity concentrations from beaches along the coastline.

\begin{tabular}{ccccc}
\hline & \multicolumn{4}{c}{ Mean activity concentration $\mathrm{Bq} \cdot \mathrm{kg}^{-1}$} \\
\hline & ${ }^{238} \mathrm{U}$ & ${ }^{232} \mathrm{Th}$ & ${ }^{40} \mathrm{~K}$ & Location \\
\hline 1. & $142.79 \pm 3.1$ & $29.69 \pm 1.2$ & $359.78 \pm 1.6$ & Walvis Bay Beach \\
2. & $199.76 \pm 8.7$ & $42.47 \pm 2.8$ & $611.19 \pm 3.2$ & Swakopmund Beach \\
3. & $176.44 \pm 3.5$ & $41.16 \pm 1.9$ & $354.38 \pm 1.5$ & Henties Bay Beach \\
Average & $173.00 \pm 8.8$ & $37.77 \pm 2.7$ & $441.78 \pm 2.5$ & \\
\hline
\end{tabular}

Table 6. Absorbed dose rate, annual effective dose rate using the UNSCEAR and present factor and the world average value.

\begin{tabular}{lccc}
\hline & Absorbed dose & \multicolumn{2}{c}{ Annual effective dose rate $\left(\mu \mathrm{Sv} \cdot \mathrm{y}^{-1}\right)$ outdoor } \\
\hline Location & Rate $\left(\mathrm{nGy} \cdot \mathrm{h}^{-1}\right)$ & UNSCEAR factor & Present factor \\
\hline 1. Walvis Bay & $93.27 \pm 0.61$ & $21.01 \pm 0.46$ & $292.60 \pm 1.45$ \\
2. Swakopmund & $44.01 \pm 0.41$ & $76.61 \pm 2.074$ & $13.63 \pm 2.64$ \\
3. Henties Bay & $105.95 \pm 1.71$ & $29.94 \pm 1.063$ & $11.86 \pm 1.09$ \\
4. Average & $114.41 \pm 1.81$ & $42.52 \pm 2.083$ & $39.36 \pm 2.76$ \\
5. WAV & 51.0 & 70.0 & 70.0 \\
\hline
\end{tabular}

WAV world average value (UNSCEAR).

The AEDR (Outdoor) using the UNSCEAR factor ranges from 121.01 to $176.61 \mu \mathrm{Sv} \cdot \mathrm{y}^{-1}$ with an average value of $142.52 \mu \mathrm{Sv} \cdot \mathrm{y}^{-1}$. The AEDR for the present factor was calculated to range from 292.60 to 413.63 $\mu \mathrm{Sv} \cdot \mathrm{y}^{-1}$ with an average value of 339.36. Although, this study showed that the AEDR using the UNSCEAR factor and the present factor have values higher than the world average value of $70 \mu \mathrm{Sv} \cdot \mathrm{y}^{-1}$, the present factor have however showed that the estimated outdoor effective dose to the population who visit the coastline for different activities would be underestimated by $\sim 24 \%$ if the UNSCEAR factor is employed. The increase in this present factor can be attributed to the arid weather condition of the country and the serenity the coastline provides to its visitor. The values obtained for AEDR in this study agree with values found by other studies which give credence to our methodology and objective of study. The current study did not evaluate the indoor effective dose because the essential data on the average concentration of radon build-up in indoor atmosphere along the 
coastline were not available.

\section{Conclusion}

This study has attempted to model a mathematical representation of time spent for outdoor and indoor activities for the coastline of the Erongo region of Namibia. The result obtained has been used to evaluate the occupancy factor for outdoor/indoor activities by the population involved in leisure, occupational or other activities. The average time spent for outdoor activities is given by $11.46 \mathrm{~h}$ and indoor with a value of $12.54 \mathrm{~h}$. This value has been shown to be significantly higher than the world value by 2.4 times (outdoor) and below the world value by $35 \%$ indoor. The factors suggest that the effective dose to population along the coastline would be underestimated by $24 \%$ for outdoor if the world average value by UNSCEAR is used. Equally, the mean values obtained for AEDR are found to be higher than the world average values $\left(70 \mu \mathrm{Sv} \cdot \mathrm{y}^{-1}\right)$ [1]. This finding is in agreement with previous studies [20] [21] where an increase outdoor factor over UNSCEAR value is attributed to differences in lifestyle and occupational activities.

\section{Acknowledgements}

Thanks are due to the International Centre for Environmental and Nuclear Sciences, University of the West Indices Mona Campus, Kingston, Jamaica for helping with gamma spectrometric analysis. We gratefully acknowledge Mr. Lawrence Olotu for his assistance in fieldwork.

\section{References}

[1] United Nation Scientific Committee on the Effect of Atomic Radiation (UNSCEAR) (2000) Report to the General Assembly. Annex B: Exposure from Natural Radiation Sources.

[2] Oni, M.O., Farai, I.P. and Awodugba, A.O. (2011) Natural Radionuclide Concentrations and Radiological Impact Assessment of River Sediments of the Coastal Area of Nigeria. Journal of Environmental Protection, 2, 418-423. http://dx.doi.org/10.4236/jep.2011.24047

[3] Salahel Din, K. and Vesterbacka, P. (2010) Spatial Distribution of Uranium Isotopes in Sea-Water Sediment, Red Sea, Egypt. Environmental Radioactivity, 101, 165-169. http://dx.doi.org/10.1016/j.jenvrad.2009.10.001

[4] Ramasamy, V., Senthil, S., Meenakshisundaram, V. and Gajendran, V. (2009) Measurement of Natural Radioactivity in Beach Sediments from North East Coast of Tamilnadu, India. Research Journal of Applied Science Engineering and Technology, 1, 54-58.

[5] Usikalu, M.R., Maleka, P.P., Malik, M., Oyeyemi, K.D. and Adewoyin, O.O. (2015) Assessment of Geogenic Natural Radionuclide Contents of Soil Samples Collected from Ogun State, South Western, Nigeria. International Journal of Radiation Research, 13, 355-361.

[6] Harb, S., Salahel, D.K.., Abbady, D.K. and Mostafa, M. (2010) Activity Concentration for Surface Soil Samples Collected from Armant, Qena, Egypt. Proceedings of the 4th Environmental Physics Conference, 4, 49-57.

[7] El-Gamal, A., Nasr, S. and El-Taher, A. (2007) Study of the Spatial Distribution of Natural Radioactivity in Upper Egypt Nile River Sediments. Radiation Measurements, 42, 457-465. http://dx.doi.org/10.1016/j.radmeas.2007.02.054

[8] Krmar, M., Slivka, J., Varga, E., Bikit, I., and Veskovic, M. (2009) Correletion of Natural Radionuclides in Sediment from Danube. Journal of Geochemical Exploration, 100, 20-24. http://dx.doi.org/10.1016/j.gexplo.2008.03.002

[9] Jibiri, N.N., Mabawonku, A.O., Oridate, A.A. and Ujiagbedion, C. (1999) Natural Radioactivity Concentration Levels in Soil and Water around a Cement Factory at Ewekoro, Ogun State Nigeria. Nigerian Journal of Physics, 11, 12-16.

[10] Federal Environmental Protection Agency (FEPA) (1991) National Interim Guidelines and Standards for Industrial Effluents, Gaseous Emissions and Hazardous Wastes Management in Nigeria.

[11] Avwiri, G., Enyinna, P. and Agbalagba, E. (2007) Terrestrial Radiation around Oil and Gas Facilities in Ughelli Nigeria. Journal of Applied Sciences, 7, 1543-1546. http://dx.doi.org/10.3923/jas.2007.1543.1546

[12] Lagarde, F. (2003) Methodology Issues in Epidemiological Assessment of Health Effects of Low-Dose Ionizing Radiation. Radiation Protection Dosimetry, 104, 297-313. http://dx.doi.org/10.1093/oxfordjournals.rpd.a006193

[13] Gransty, B.J. and LaMarre, J.R. (2004) The Annual Effective Dose from Natural Sources of Ionizing Radiation in Canada. Protection Dosimetry, 108, 215-226. http://dx.doi.org/10.1093/rpd/nch022

[14] Taskin, M., Karavus, M., Ay, M.P., Topuzoglu, A., Hindiroglu, S., and Karahan, G. (2009) Radionuclide Concentrations in Soil and Lifetime Cancer Risk Die to the Gamma Radioactivity in Kirklareli, Turkey. Journal of Environmental Radioactivity, 100, 49-53. http://dx.doi.org/10.1016/j.jenvrad.2008.10.012 
[15] Steinhausler, F. and Lettner. H. (1992) Radiometric Survey in Namibia. Radiation Dosimetry, 1, 553-555.

[16] Oyedele, J.A., Shimboyo, S., Sitoka, S. and Gaoseb, F. (2010) Assessment of Natural Radioactivity in the Soils of Rossing Uranium Mine and its Satellite Town in Western Namibia, Southern Africa. Nuclear Instruments and Methods in Physics Research Section A: Accelerators, Spectrometers, Detectors and Associated Equipment, 619, 467-469. http://dx.doi.org/10.1016/j.nima.2010.01.068

[17] Strategic Environmental Assessment (SEA) (2010) Central Namib Uranium Rush, Geological Survey of Namibia. Ministry of Mines and Energy, Windhoek.

[18] Brown, L. (1983) National Radiation Survey in the UK: Indoor Occupancy Factors. Radiation Protection Dosimetry, 5, 1-7.

[19] United Nation Scientific Committee on the Effect of Atomic Radiation (UNSCEAR) (1998) Report to the General Assembly. Annex B: Sources and Effects of Ionizing Radiation.

[20] Arogunjo, A.M. and Adekola, A.S. (2007) Occupancy Factor Model for Exposure to Atmospheric Radiation by Urban and Rural Dwellers in Nigeria. Journal of Applied Sciences, 7, 1343-1346. http://dx.doi.org/10.3923/jas.2007.1343.1346

[21] Arogunjo, A.M., Ohenhen, H.O. and Olowookere, S.P. (2004) A Re-Evaluation of the Occupancy Factors for Effective Dose Estimation in Tropical Environment. Radiation Protection Dosimetry, 1-7.

[22] NPC (2011) Namibia 2011 Population and Housing Census Preliminary Results. www.gov.na/do.cuments/.../0ea026d4-9697-4851-a693-1b97a1317c60 